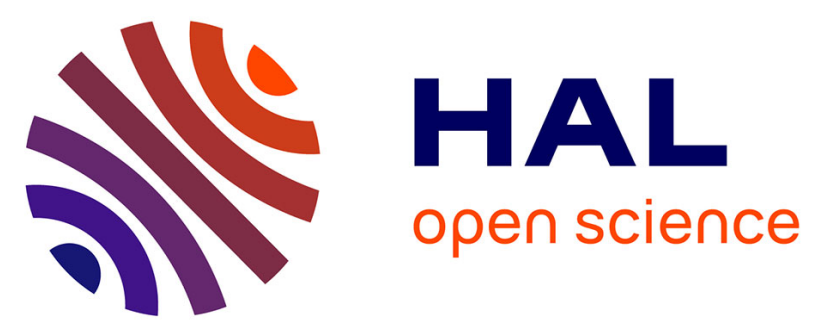

\title{
Three-Dimensional Radical Covalent Organic Frameworks as Highly Efficient and Stable Catalysts for Selective Oxidation of Alcohols
}

Fengqian Chen, Xinyu Guan, Hui Li, Jiehua Ding, Liangkui S Zhu, Bin Tang, Valentin Valtchev, Yushan Yan, Shilun Qiu, Qianrong Fang

\section{To cite this version:}

Fengqian Chen, Xinyu Guan, Hui Li, Jiehua Ding, Liangkui S Zhu, et al.. Three-Dimensional Radical Covalent Organic Frameworks as Highly Efficient and Stable Catalysts for Selective Oxidation of Alcohols. Angewandte Chemie, 2021, 133 (41), pp.22404-22409. 10.1002/ange.202108357 . hal03424272

\section{HAL Id: hal-03424272 \\ https://hal.science/hal-03424272}

Submitted on 10 Nov 2021

HAL is a multi-disciplinary open access archive for the deposit and dissemination of scientific research documents, whether they are published or not. The documents may come from teaching and research institutions in France or abroad, or from public or private research centers.
L'archive ouverte pluridisciplinaire HAL, est destinée au dépôt et à la diffusion de documents scientifiques de niveau recherche, publiés ou non, émanant des établissements d'enseignement et de recherche français ou étrangers, des laboratoires publics ou privés. 


\title{
Three-Dimensional Radical Covalent Organic Frameworks as Highly Efficient and Stable Catalysts for Selective Oxidation of Alcohols
}

\author{
Fengqian Chen, ${ }^{\dagger}$ Xinyu Guan, ${ }^{\dagger}$ Hui Li, * Jiehua Ding, Liangkui Zhu, Bin Tang, * Valentin Valtchev, \\ Yushan Yan, Shilun Qiu, and Qianrong Fang*
}

[*] F. Chen, Dr. X. Guan, Dr. H. Li, J. Ding, Dr. L. Zhu, Prof. S. Qiu, Prof. Q. Fang

State Key Laboratory of Inorganic Synthesis and Preparative Chemistry, Jilin University, Changchun 130012, China

E-mail: qrfang@jlu.edu.cn or postlh@jlu.edu.cn

Dr. B. Tang

Deakin University, Institute for Frontier Materials, Geelong, Victoria 3216, Australia

F-mail: bin.tang@deakin.edu.au

Prof. V. Valtchev

Qingdao Institute of Bioenergy and Bioprocess Technology, Chinese Academy of Sciences 89 Song Ling Rd, Qingdao, Shandong 266101,

China;

Normandie Univ, ENSICAEN, UNICAEN, CNRS, Laboratoire Catalyse et Spectrochimie, 6 Marechal Juin, 14050 Caen, France

Prof. Y. Yan

Department of Chemical and Biomolecular Engineering, Center for Catalytic Science and Technology, University of Delaware, Newark, DE 19716, USA

$[\dagger]$ These authors contributed equally to this work. author.

\begin{abstract}
With excellent designability, large accessible inner surface, and high chemical stability, covalent organic frameworks (COFs) are promising candidates as metal-free heterogeneous catalysts. In this work, we, for the first time, report two three-dimensional (3D) radicalbased COFs, termed JUC-565 and JUC-566, in which radical moieties (2,2,6,6-tetramethylpiperidine-1-oxy, TEMPO) are uniformly decorated on the channel walls via a bottom-up approach. Based on grafted functional groups and suitable regular channels, these materials open up the application of COFs as highly efficient and selective metal-free redox catalysts in aerobic oxidation of alcohols to relevant aldehydes or ketones with outstanding turn over frequency (TOF) up to $132 \mathrm{~h}^{-1}$, which has exceeded other TEMPO-modified catalytic materials tested under similar conditions. Meanwhile, these stable COF-based catalysts could be easily recovered and reused for multiple runs. This study thus promotes $3 \mathrm{D}$ functional COFs anchored with stable radicals for potential applications in organic synthesis and material science.
\end{abstract}

Keywords: covalent organic frameworks $\cdot$ radical $\cdot$ functionalization $\cdot$ selective $\cdot$ oxidation of alcohol

Covalent organic frameworks $(\mathrm{COFs}),{ }^{[1]}$ an emergency class of crystalline porous organic materials, are considered as promising platforms for heterogeneous chemical catalysis, owning to their highly designable organic skeletons, abundant highly accessible active sites, and excellent chemical stabilities. After the first report of COF-based catalyst (Pd/COF-LZU1) by Wang and co-workers in 2011, ${ }^{[2 a]}$ some relative works have been reported. ${ }^{[2]}$ For example, we have recently developed a series of three-dimensional (3D) COF-based catalysts by the functional design, ${ }^{[3]}$ including $3 \mathrm{D}$ base-functionalized COFs for highly selective catalysis in Knoevenagel condensation reactions, ${ }^{[3 a]} 3 \mathrm{D}$ COFs with dual linkages as bifunctional catalysts for one-pot cascade reactions, ${ }^{[3 b]}$ and $3 \mathrm{D}$ metal-containing Salphen COFs as catalytic antioxidants for the removal of superoxide radicals. ${ }^{[3 \mathrm{c}]}$ Often the catalytic active component (such as metal ions and nanoparticles) of a large portion of COF catalysts are incorporated through weak interaction, which potentially leads to leach or or agglomeration of the active phase during catalytic reaction. Thus the stability and reusability of these materials are thus insufficient to be used as industrial catalysts. Therefore, bare COF skeletons have attracted broad interests as metal-free heterogeneous chemical catalysts, in which active sites were covalently bound on the backbone. Among these materials, strong covalent bonds promised high chemical stability and excellent reusability, while the exposed organic functional groups served as catalytic centers. However, the development of such COF-based catalysts with high stability and catalytic activity remains a great challenge. 


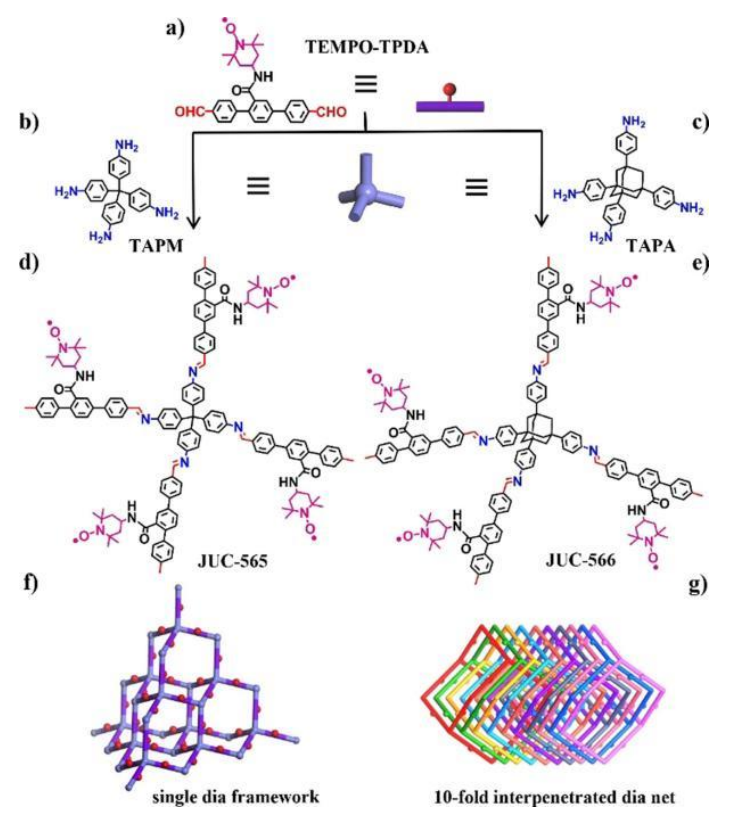

Scheme 1. Strategy for constructing 3D radical-based COFs. Molecular structures of TEMPO-TPDA (a) as a linear 2-connected building unit as well as TAPM (b) or TAPA (c) as a tetrahedral 4-connected building unit. Two novel 3D radical-based COFs, JUC-565 (d) and JUC566 (e), prepared by the condensation reaction of TEMPO-TPDA and TAPM or TAPA. A single dia framework (f) and 10-fold interpenetrated dia net $(\mathrm{g})$ in $3 \mathrm{D}$ radical-based COFs.

The stable organic nitroxyl radicals, such as 2,2,6,6-tetramethylpiperidine-1-oxy (TEMPO), have been widely studied as highly efficient metal-free redox catalysts. ${ }^{[4]}$ Individual TEMPO molecules and their derivatives have been employed in a broad range of chemical transformations, but the recovery and reuse of catalysts are highly desirable since TEMPO is considerably expensive. As a result, various supporting materials have been studied for the immobilization of TEMPO, such as silica, amorphous polymers, and metal-organic frameworks (MOFs) ${ }^{[5]}$ However, it was still difficult to prepare catalysts combining excellent recyclability and high catalytic activity due to irregular pores or poor stability in traditional supporting materials. In our considerations, COFs might be promising candidates for TEMPO immobilization and corresponding redox catalysis due to their large exposed inner surface, uniform nano-channels, highly designable structures, and excellent chemical stability. Nevertheless, only a few reports of TEMPO-decorated COFs were available to date, ${ }^{[6]}$ and they were limited to post-modified 2D frameworks, which has extremely restricted their performance.
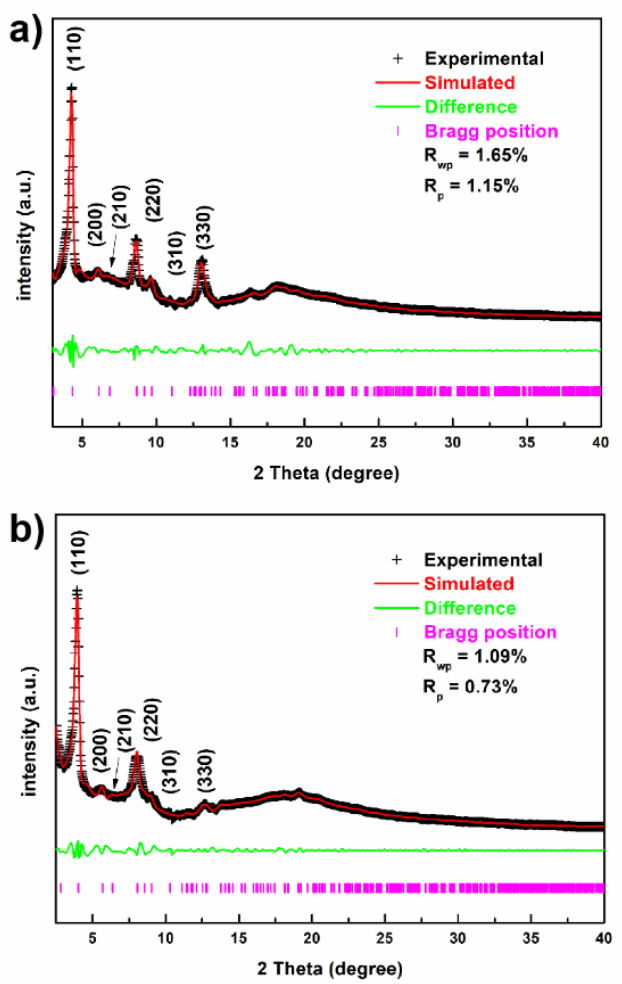

Figure 1. PXRD patterns of JUC-565 (a) and JUC-566 (b). 
Herein, we report two 3D TEMPO-based COFs via bottom-up strategy, termed JUC-565 and JUC-566. Different from previously reported 2D TEMPO-based COFs, TEMPO groups as radical moieties were uniformly anchors on the channel walls with high density. Since the whole framework was connected via strong covalent bonds, these materials showed high chemical stability in strong basic or acidic aqueous solutions. Based on rich radical units, interconnected channels and outstanding stability, these functional COFs have been demonstrated to be highly selective and reusable metal-free redox catalysts for the application in aerobic oxidation of alcohols to relevant aldehydes or ketones with remarkable turnover frequency (TOF) as high as $132 \mathrm{~h}^{-1}$, which is the highest ever reported. To the best of our knowledge, this study represents the first case of 3D functional COFs decorated by TEMPO radicals and their application as metal-free redox catalysts for aerobic oxidation of alcohols.

The synthesis of 3D radical-based COFs was carried out by solvothermal condensation of TEMPO-TPDA (TPDA = $\left[1,1^{\prime}: 4^{\prime}, 1^{\prime \prime}-\right.$ terphenyl]-4,4"-dicarbaldehyde), and 1,3,5,7-tetrakis(4-aminophenyl) adamantane (TAPA) or tetra(4-aminophenyl)methane (TAPM) in a mixture of dioxane, mesitylene, and acetic acid at $120{ }^{\circ} \mathrm{C}$ for 3 days (Scheme 1). A variety of methods have been utilized for structural confirmation. Scanning electron microscopy (SEM, Figures S1 and S2) images demonstrated isometric nanocrystals building random aggregates for both COFs. Fourier transform infrared (FT-IR) spectra showed new peaks at $1658 \mathrm{~cm}^{-1}$ for both COFs, which is a typical characteristic of the imine bond. At the same time, almost complete disappearance of $\mathrm{C}=\mathrm{O}\left(1696 \mathrm{~cm}^{-1}\right.$ for TEMPO-TPDA $)$ and N-H stretching $\left(\sim 3332 \mathrm{~cm}^{-1}\right.$ for TAPA and $\sim 3394 \mathrm{~cm}^{-1}$ for TAPM) proved well transformation of aldehyde and amine groups (Figures S3 and S4). Furthermore, thermogravimetric analysis (TGA) illustrated good thermal stability $\left(\sim 300{ }^{\circ} \mathrm{C}\right.$ under $\left.\mathrm{N}_{2}\right)$ of $3 \mathrm{D}$ radical-based COFs (Figures S5 and S6). Outstanding chemical stability was also proved by the preserved PXRD patterns after immersing in different organic solvents and strong basic $(1 \mathrm{M} \mathrm{NaOH})$ or acidic $(1 \mathrm{M} \mathrm{HCl})$ aqueous solutions for one week (Figures S7-10). Moreover, the radical character was probed by electron paramagnetic resonance (EPR) spectroscopy at room temperature showing peaks at $\mathrm{g}=2.0096$ for JUC-565 and 2.0097 for JUC566 , respectively, which is well consistent with that of TEMPO radical ( $g=2.0097$, Figures S12-14).

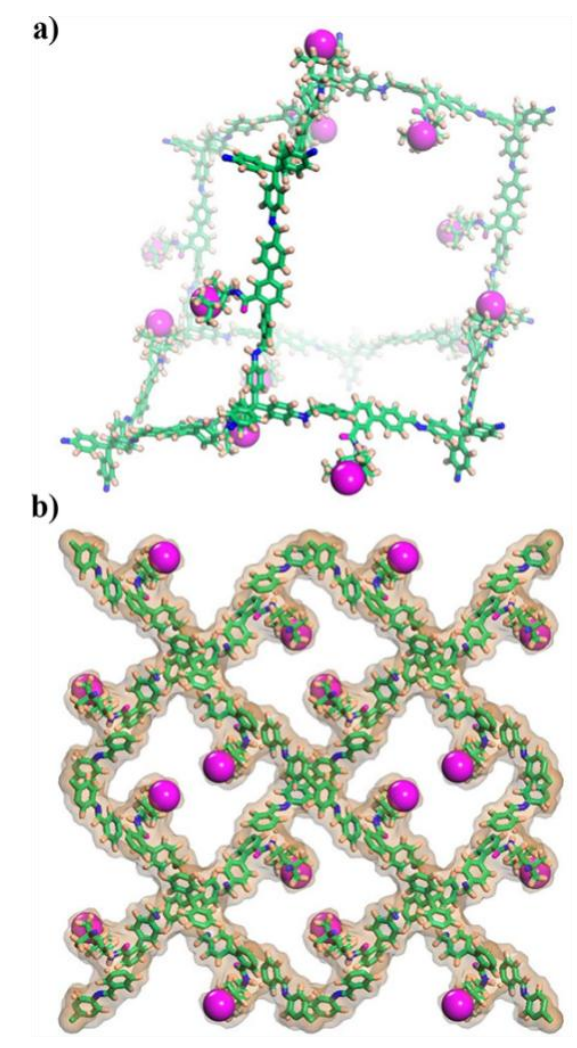

Figure 2. Extended structure of JUC-565: (a) single dia network and (b) 3D porous framework viewed along the c axis. The pink balls represent TEMPO radicals. C, green; $\mathrm{H}$, yellow, $\mathrm{N}$, blue; O, pink.

The crystalline structures were verified by the powder X-ray diffraction (PXRD) and structural simulations (Figure 1). After a geometrical energy minimization by the Materials Studio software package ${ }^{[7]}$ based on 10-fold interpenetrated dia nets and disordered pendant functional groups, ${ }^{[8]}$ their unit cell parameters were acquired $\left(a=b=28.838 \AA, c=7.1132 \AA\right.$ and $\alpha=\beta=\gamma=90^{\circ}$ for JUC-565; $a=b$ $=31.438 \AA, c=7.6704 \AA$ and $\alpha=\beta=\gamma=90^{\circ}$ for JUC-566; Tables S2 and S3). The simulated PXRD patterns were in good agreement with the experimental ones. Moreover, the experimental PXRD patterns were carried out by full profile pattern matching (Pawley) refinements. Peaks at 4.31, 6.14, 6.76, 8.68, 9.77 and $13.15^{\circ}$ for JUC-565 belong to the (110), (200), (210), (220), (310), and (330) Bragg peaks of space group P-4 (No. 81); peaks at 3.97, 5.70, 6.39, 8.05, 9.01 and $12.54^{\circ}$ for JUC-566 correspond to the (110), (200), (210), (220), (310), and (330) Bragg peaks of the space group P-4 (No. 81). The calculated results were well consistent with the measured ones with good agreement 
factors $(R \mathrm{p}=1.15 \%$ and $\omega R \mathrm{p}=1.65 \%$ for JUC-565; $R \mathrm{p}=0.73 \%$ and $\omega R \mathrm{p}=1.09 \%$ for JUC-566). In addition, we also tried alternative structures with 9- or 11-fold interpenetrated dia topology; however, there was an apparent difference between the simulated and experimental PXRDs (Figures S15-22). Also, the PXRD pattern of JUC-565 was in good agreement with that of LZU-79 with an approximate length of linkers, and 10-fold interpenetrated dia net, which has been proved by its single-crystal X-ray diffraction (Figure $\mathrm{S} 23) .{ }^{[9]}$ In terms of these results, the obtained COFs are proposed to be the expected architectures possessing microporous channels ( 0.8 $\mathrm{nm}$ for JUC-565 and $\sim 0.9 \mathrm{~nm}$ for JUC-566), which are uniformly decorated by TEMPO radicals (Figure 2 and Figure S24).
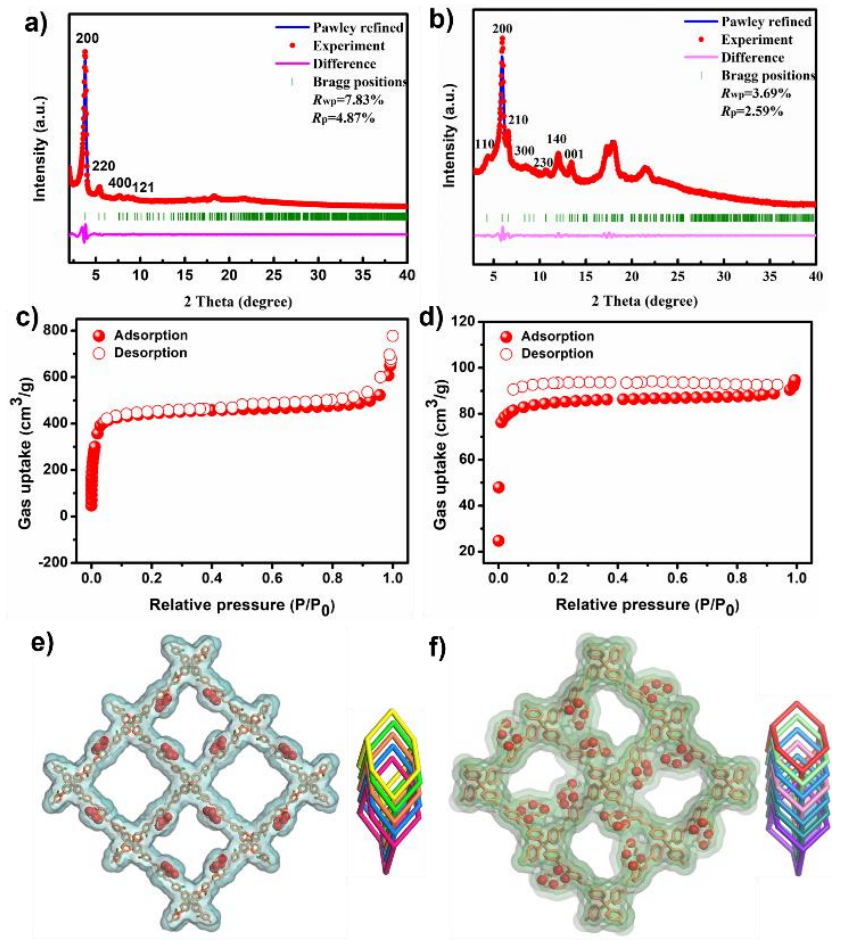

Figure 3. $\mathrm{N}_{2}$ adsorption-desorption isotherms at $77 \mathrm{~K}$ for JUC-565 (a) and JUC-566 (b). Inset: pore-size distribution calculated by fitting on the NLDFT model to the adsorption data.

The porosity and specific surface areas of 3D radical-based COFs were determined by $\mathrm{N}_{2}$ adsorption measurements at $77 \mathrm{~K}$. As shown in Figure 3, both COFs exhibited sharp gas uptake at low pressure (below $0.1 \mathrm{P} / \mathrm{P}_{0}$ ), which reveals their microporous nature. An inclination of the isotherm in the $0.8-1.0 \mathrm{P} / \mathrm{P}_{0}$ range and slight desorption hysteresis can be observed due to the presence of textural mesopores. ${ }^{[10]}$ The Brunauer-Emmett-Teller (BET) surface areas were calculated as $313 \mathrm{~m}^{2} / \mathrm{g}$ for JUC-565 and $482 \mathrm{~m}^{2} / \mathrm{g}$ for JUC-566 (Figures S25 and S26), which are much higher than those from $2 \mathrm{D}$ radical COFs, i.e., only $5.2 \mathrm{~m}^{2} / \mathrm{g}$ for [TEMPO] ${ }_{100 \%}-\mathrm{NiP}-\mathrm{COF}^{[6 \mathrm{a}]}$ and $34 \mathrm{~m}^{2} / \mathrm{g}$ for T-COF-100. ${ }^{[6 \mathrm{~b}]}$ The nonlocal density functional theory (NLDFT) was utilized to estimate their pore size distributions. Both COFs demonstrated microporous cavities with $\sim 0.9 \mathrm{~nm}$ for JUC-565 and $\sim 1.0 \mathrm{~nm}$ for JUC-566 (Figure 3, inset), which are in good agreement with pore sizes predicted from their crystal structures.

Encouraged by the abundant TEMPO radicals, good chemical stability, high surface areas and suitable regular pores of 3D radical-based COFs, JUC-566 was chosen to evaluate the catalytic performance of a metal-free heterogeneous catalyst for aerobic oxidation of hydroxyl to carbonyl. Typically, the catalytic reaction was carried out in a glass vial with COF catalyst $\left(5.0 \mathrm{~mol} \%\right.$ based on nitroxide radical), $\mathrm{NaNO}_{2}$ (30.0 $\mathrm{mol} \%)$ as dioxygen activator, 1,3-dibromo-5,5-dimethylhydantoin (DBDMH, $7.5 \mathrm{~mol} \%$ ) as co-catalyst, and anhydrous acetic acid as solvent $(\mathrm{AcOH}, 0.5 \mathrm{~mL})$ under oxygen atmosphere $\left(\mathrm{O}_{2}\right.$ balloon $)$ at room temperature. 
Table 1. Aerobic oxidation of alcohols using JUC-566 ${ }^{\mathrm{a}}$.

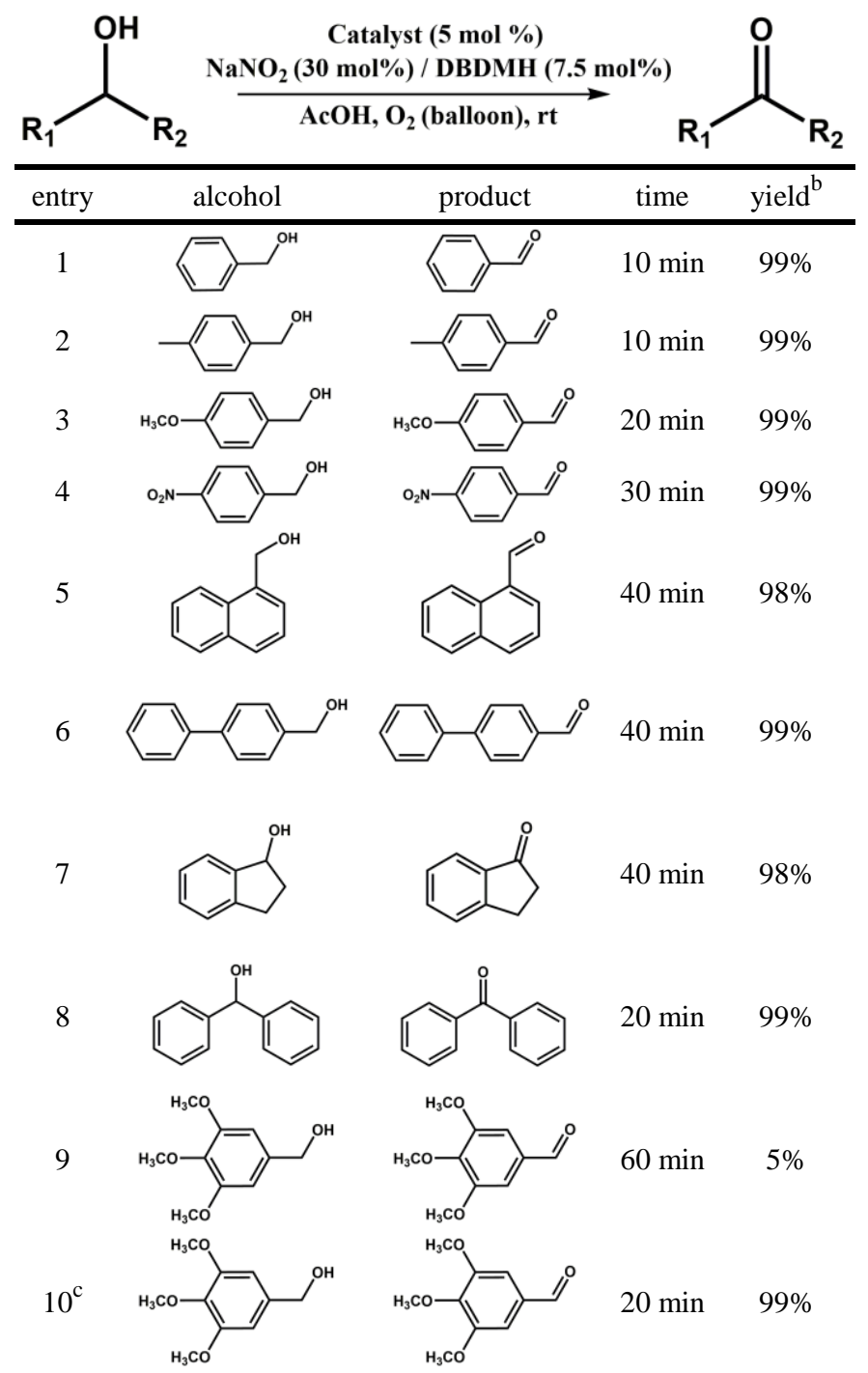

${ }^{\mathrm{a}}$ Reaction conditions: $0.2 \mathrm{mmol}$ of alcohol, $8.0 \mathrm{mg}$ of JUC-566 (5.0 mol\% of nitroxide radical), $4.2 \mathrm{mg}$ of $\mathrm{NaNO}_{2}$ (30.0 mol\%), and 4.3 $\mathrm{mg}$ of DBDMH $(7.5 \mathrm{~mol} \%)$ in $0.5 \mathrm{~mL}$ of $\mathrm{CH}_{3} \mathrm{COOH}$ with an $\mathrm{O}_{2}$ balloon at room temperature. ${ }^{b}$ Determined by ${ }^{1} \mathrm{H}$ NMR spectroscopy. ${ }^{\mathrm{c}}$ Reaction conditions: the catalyst was replaced with TEMPO molecule and all other conditions remained the same.

As shown in Table 1, successful oxidation of a broad spectrum of alcohols to corresponding carbonyl compounds with high yields was achieved. For example, the reaction of benzyl alcohol could be completed in 10 min with a $99 \%$ yield (enter 1). Notably, its turn over frequency (TOF) was calculated as high as $132 \mathrm{~h}^{-1}$, which has surpassed previous reported TEMPO-anchored materials under similar reaction conditions (Table S1), such as MOFs $\left(19.2 \mathrm{~h}^{-1}\right.$ for UiO-67-TEMPO), ${ }^{[11]}$ amorphous polymers $\left(40 \mathrm{~h}^{-1}\right.$ for TEMPO-CMP-4), ${ }^{[12]}$ ordered mesoporous silica $\left(111 \mathrm{~h}^{-1}\right.$ for SBA-15-ABNO), ${ }^{[13]}$ oxide nanoparticles $\left(125 \mathrm{~h}^{-1}\right.$ for MNST) ${ }^{[14]}$ The para-substituted benzyl alcohols could also be transformed to the corresponding aldehydes in almost quantitative yields (Table 1, entries 2-6). Meanwhile, increasing reaction time was required with larger substrates, possibly triggered by the slow diffusion through COF channels. Subsequently, the reaction was extended to some other alcohols, including secondary alcohols, which will produce ketones (entries 7 and 8 ). Noteworthy, all selected substrates demonstrated high yields, illustrating the generality of this catalysis system. To further confirm the function of JUC-566 in the catalytic 
transformation, we attempted to remove it by filtration after 15 mins of reaction, and an immediate termination of reaction was observed (Figure 4a). This result prove the heterogeneous nature of catalytic reaction.

\section{a)}

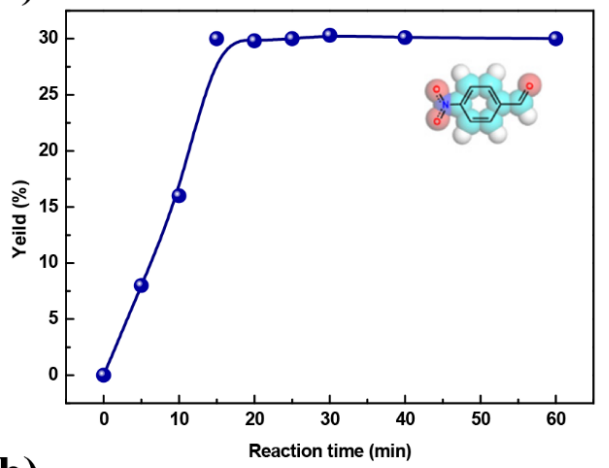

b)

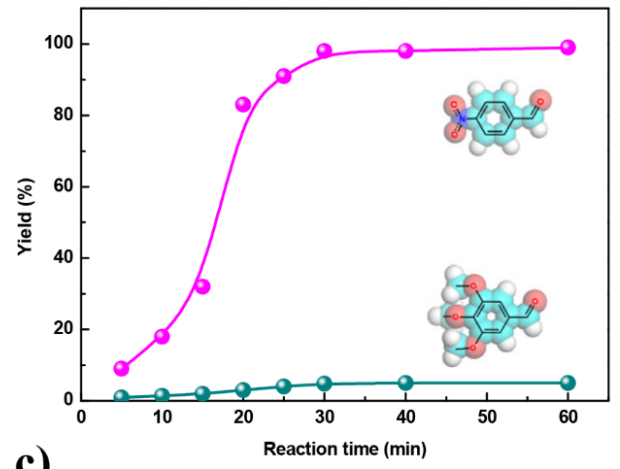

c)

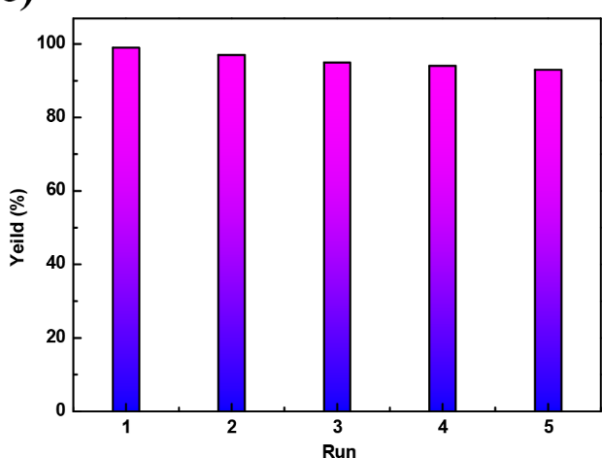

Figure 4. (a) Yield $v s$ time curve for aerobic oxidation controlled by the addition or removal of COF crystals. (b) Yield $v s$ time curves for aerobic oxidation with substrates of different sizes. (c) Recyclability study of aerobic oxidation with 4-nitrobenzyl alcohol as the substrate.

More importantly, thanks to the uniform channels of the frameworks, JUC-566 demonstrated an amazing size slectivity. For instance, only $5 \%$ of the target product was detected even after 60 min under similar conditions for 3,4,5-trimethoxybenzyl alcohol, which possessed the dimension of $1.0 \times 1.1 \mathrm{~nm}$ (larger than the aperture of JUC-566 of about $0.9 \mathrm{~nm}$, entry 9, Figure 4b). Meanwhile, a controlled experiment was also carried out with the catalysis of TEMPO molecules under similar conditions, and $99 \%$ transformation of 3,4,5-trimethoxybenzyl alcohol was achieved in 20 minutes (Table 1, entry 10). These results illustrated that the catalytic reaction took place in the COF's channels and that JUC-566 possessed excellent size selectivity over substrate dimensions. After that, the cycling performance of this catalyst was also explored with 4-nitrobenzyl alcohol as the substrate. After the reaction was completed, the catalysts could be recovered by simple filtration and used for the next run. After five cycles, a high yield of $95 \%$ could still be observed (Figure 4c). Furthermore, the preserved PXRD pattern of recovered JUC-566 confirm its structural integrity after the recycle tests (Figure S11).

In summary, through using a pre-designed TEMPO-based monomer, we develop two robust 3D radical COFs, JUC-565 and JUC-566. These materials are provided with high stability, large surface areas, suitable regular pores, abundant and accessible TEMPO moieties on the channel walls. Combining high efficiency and good reusability, 3D radical-based COFs exhibit extraordinary selective catalytic performance for aerobic oxidation of various alcohols to the corresponding aldehydes or ketones with excellent TOF up to $132 \mathrm{~h}^{-1}$, which is much higher than other reported TEMPO-decorated catalytic materials under similar conditions, including MOFs, silica, amorphous polymers, and oxide nanoparticles. These results thus open an avenue towards designing 3D functionalized COFs and promote their applications in organic synthesis and material science. 


\section{Acknowledgments}

This work was supported by National Natural Science Foundation of China (22025504, 21621001, and 21390394), "111" project (BP0719036 and B17020), China Postdoctoral Science Foundation (2020TQ0118 and 2020M681034), and the program for JLU Science and Technology Innovative Research Team. V.V., Q.F. and S.Q. acknowledge the collaboration in the framework of ChinaFrench joint laboratory "Zeolites".

\section{Conflict of interest}

The authors declare no conflict of interest.

Received: ((will be filled in by the editorial staff))

Published online on ((will be filled in by the editorial staff))

\section{Reference}

[1] a) A. P. Côté, A. I. Benin, N. W. Ockwig, M. O'Keeffe, A. J. Matzger, O. M. Yaghi, Science 2005, 310, 1166-1170; b) H. M. El-Kaderi, J. R. Hunt, J. L. Mendoza-Cortes, A. P. Côté, R. E. Taylor, M. O'Keeffe, O. M. Yaghi, Science 2007, 316, 268-272; c) X. Feng, X. S. Ding, D. L. Jiang, Chem. Soc. Rev. 2012, 41, 6010-6022; d) S. Y. Ding, W. Wang, Chem. Soc. Rev. 2013, 42, 548-568; e) J. W. Colson, W. R. Dichtel, Nat. Chem. 2013, 5, 453-465; f) M. S. Lohse, T. Bein, Adv. Funct. Mater. 2018, 28, 1705553; g) Z. F. Wang, S. N. Zhang, Y. Chen, Z. J. Zhang, S. Q. Ma, Chem. Soc. Rev. 2020, 49, 708735; h) X. Y. Guan, F. Q. Chen, Q. R. Fang, S. L. Qiu, Chem. Soc. Rev. 2020, 49, 1357-1384; i) Y. Yusran, X. Y. Guan, H. Li, Q. R. Fang, S. L. Qiu, Natl. Sci. Rev. 2020, 7, 170-190; j) Y. Yusran, Q. R. Fang, V. Valtchev, Adv. Mater. 2020, 32, 2002038.

[2] a) S. Y. Ding, J. Gao, Q. Wang, Y. Zhang, W. G. Song, C. Y. Su, W. Wang, J. Am. Chem. Soc. 2011, 133, 19816-19822; b) L. Stegbauer, K. Schwinghammer, B. V. Lotsch, Chem. Sci. 2014, 5, 2789-2793; c) S. Lin, C. S. Diercks, Y. B. Zhang, N. Kornienko, E. M. Nichols, Y. Zhao, A. R. Paris, D. Kim, P. Yang, O. M. Yaghi, C. J. Chang, Science 2015, 349, 1208-1213; d) H. Xu, J. Gao, D. L. Jiang, Nat. Chem. 2015, 7, 905-912; e) X. Wang, L. Chen, S. Y. Chong, M. A. Little, Y. Wu, W. H. Zhu, R. Clowes, Y. Yan, M. A. Zwijnenburg, R. S. Sprick, A. I. Cooper, Nat. Chem. 2018, 10, 1180-1189; f) X. R. Wang, X. Han, J. Zhang, X. W. Wu, Y. Liu, Y. Cui, J. Am. Chem. Soc. 2016, 138, 12332-12335; g) S. M. J. Rogge, A. Bavykina, J. Hajek, H. Garcia, A. I. Olivos-Suarez, A. Sepúlveda-Escribano, A. Vimont, G. Clet, P. Bazin, F. Kapteijn, M. Daturi, E. V. Ramos-Fernandez, F. X. Llabrés i Xamena, V. Van Speybroeck, J. Gascon, Chem. Soc. Rev. 2017, 46, 3134-3184; h) J. Guo, D. L. Jiang, ACS Cent. Sci. 2020, 6, 869-879; i) Y. Yusran, H. Li, X. Y. Guan, Q. R. Fang, S. L. Qiu, EnergyChem 2020, 2, 100035.

[3] a) Q. R. Fang, S. Gu, J. Zheng, Z. B. Zhuang, S. L. Qiu, Y. S. Yan, Angew. Chem. Int. Ed. 2014, 53, 2878-2882; Angew. Chem. 2014, 126, 2922-2926; b) H. Li, Q. Y. Pan, Y. C. Ma, X. Y. Guan, M. Xue, Q. R. Fang, Y. S. Yan, V. Valtchev, S. L. Qiu, J. Am. Chem. Soc. 2016, 138, 14783-14788; c) S. C. Yan, X. Y. Guan, H. Li, D. H. Li, M. Xue, Y. S. Yan, V. Valtchev, S. L. Qiu, Q. R. Fang, J. Am. Chem. Soc. 2019, 141, 2920-2924; d) Y. C. Ma, X. Z. Liu, X. Y. Guan, H. Li, Y. Yusran, M. Xue, Q. R. Fang, Y. S. Yan, S. L. Qiu, V. Valtchev, Dalton Trans. 2019, 38, 7352-7357; e) D. H. Li, C. Y. Li, L. J. Zhang, H. Li, L. K. Zhu, D. J. Yang, Q. R. Fang, S. L. Qiu, X. D. Yao, J. Am. Chem. Soc. 2020, 142, 8104-8108.

[4] a) A. E. De Nooy, A. C. Besemer, H. van Bekkum, Synthesis 1996, 10, 1153-1176; b) S. Wertz, A. Studer, Green. Chem. 2013, 15, 3116-3134.

[5] a) H. A. Beejapur, Q. Zhang, K. C. Hu, L. Zhu, J. L. Wang, and Z. B. Ye, ACS Catalysis 2019, 9, 2777-2830; b) S. Kim, H. E. Lee, J. M. Suh, M. H. Lim, M. Kim, Inorg. Chem. 2020, 59, 17573-17582; c) B. Karimi, B. Ghaffari, H. Vali, J. Colloid Interf. Sci. 2021, 589, 474-485.

[6] a) F. Xu, H. Xu, X. Chen, D. C. Wu, Y. Wu, H. Liu, C. Gu, R. W. Fu, D. L. Jiang, Angew. Chem. Int. Ed. 2015, 54, 6814-6818; Angew. Chem. 2015, 127, 6918-6922; b) B. K. Hughes, W. A. Braunecker, D. C. Bobela, S. U. Nanayakkara, O. G. Reid, J. C. Johnson, J. Phys. Chem. Lett. 2016, 7, 36603665 ; c) S. Wang, Q. Wang, P. Shao, Y. Han, X. Gao, L. Ma, S. Yuan, X. Ma, J. Zhou, X. Feng, B. Wang, J. Am. Chem. Soc. 2017, 139, 4258-4261; d) W. Cao, W. D. Wang, H. S. Xu, I. V. Sergeyev, J. Struppe, X. L. Wang, F. Mentink-Vigier, Z. H. Gan, M. X. Xiao, L. Y. Wang, G. P. Chen, S. Y. Ding, S. Bai, W. Wang, J. Am. Chem. Soc. 2018, 140, 6969-6977.

[7] Materials Studio ver. 7.0; Accelrys Inc.; San Diego, CA.

[8] C. Bonneau, O. Delgado-Friedrichs, M. O'Keeffe, O. M. Yaghi, Acta Crystallogr. Sect. A 2004, 60, 517-520.

[9] T. Q. Ma, E. A. Kapustin, S. X. Yin, L. Liang, Z. Y. Zhou, J. Niu, L. H. Li, Y. Y. Wang, J. Su, J. Li, X. G. Wang, W. D. Wang, W. Wang, J. L. Sun, O. M. Yaghi, Science 2018, 361, 48-52.

[10] a) Y. C. Ma, Y. J. Wang, H. Li, X. Y. Guan, B. J. Li, M. Xue, Y. S. Yan, V. Valtchev, S. L. Qiu, Q. R. Fang, Angew. Chem. Int. Ed. 2020, 59, 1963319638; Angew. Chem. 2020, 132, 19801-19806; b) H. Li, J. H. Ding, X. Y. Guan, F. Q. Chen, C. Y. Li, L. K. Zhu, M. Xue, D. Q. Yuan, V. Valtchev, Y. S. Yan, S. L. Qiu, Q. R. Fang, J. Am. Chem. Soc. 2020, 142, 13334-13338; c) H. Li, F. Q. Chen, X. Y. Guan, J. L. Li, C. Y. Li, B. Tang, V. Valtchev, Y. S. Yan, S. L. Qiu, Q. R. Fang, J. Am. Chem. Soc. 2021, 143, 2654-2659.

[11] K. M. Zwoliński, M. J. Chmielewski, ACS Appl. Mater. Interfaces 2017, 9, 33956-33967.

[12] M. Liu, B. Zhou, L. Zhou, Z. Xie, S. Li, L. Chen, J. Mater. Chem. A 2018, 6, 9860-9865.

[13] B. Karimi, E. Farhangi, H. Vali, S. Vahdati, ChemSusChem 2014, 7, 2735-2741.

[14] B. Karimi, E. Farhangi, Chem. Eur. J. 2011, 17, 6056-6060. 